\title{
Evaluation of Safety and Efficacy of Radiofrequency Lesioning of Thoracic Dorsal Root Ganglion in Chest Cancer Pain Patients
}

Ahmed El-Saeed Abdelrahman*, Rafaat Mahfouz Reyad*, Ayman Mohamady El-Demerdosh*, Mahmoud Mohamed Hassan Mostafa*

*Department of Anesthesia \& ICU Department, Faculty of Medicine, Aswan University Corresponding author: Mahmoud Mohamed Hassan Mostafa, Mobile: 00201000553088,

E-Mail: dr_moody2001@yahoo.com

\begin{abstract}
Background: since cancer-associated pain is a common occurrence in malignancies involving the chest. In these cases, pain is complex and may have visceral, somatic or neuropathic components. It has been noticed that the number of cancer patients with refractory chest pain is increasing with more cancer prevalence, also with the advances in therapy and prolonged life expectancy. The demand for interventional procedures to control pain for these patients also increases. Interventional pain procedures are indicated for refractory pain when analgesic drugs are ineffective or associated with intolerable side effects. In controlling cancer pain it is commonly inadequately managed for these patients leading to suffer form of physical disabilities, psychological disturbance and avoiding treatment. Aim of the work: this study was designed to test both the efficacy and safety of thermo-coagulative ablation of the thoracic dorsal root ganglia for pain control in cancer patients that have refractory chest pain. Methodology: this prospective randomized study was conducted in the National Cancer Institute, Cairo University and Aswan University after board approval from October 2016 to March 2018. Sixty-five patients with Refractory Chronic Chest Cancer Pain were selected randomly and prospectively from the pain clinic of both the National Cancer Institute of Cairo University and Aswan University, after taken an informed written consent from the patient. The complete duration of the follow up lasted 3 months post-interventional with assessments after 1 week, 1 month and 3 months. At each follow up each patient was re-assessed with the following assessments; VAS, ECOG Performance Status. Results: we found that with effective pain relief there was a significant reduction in the mean VAS values; which means that there was functional improvement, in all the postinterventional follow ups. Also, there was an improvement in the functional state of the patients throughout the follow-up post-intervention with regards to the ECOG performance status from the results.Conclusion: we concluded that thermal radiofrequency ablation is considered an alternative for treating refractory chronic chest cancer pain of several types and causes. This is because of its efficacy, safety and ease of use. It also requires a minimal hospital stay or can even be performed on an outpatient basis.
\end{abstract}

Keywords: Radiofrequency, Thoracic dorsal root, Chest cancer pain.

\section{INTRODUCTION}

The prevalence of pain in cancer patients in recent reviews reported to be $51 \%$ regardless the type and stage of cancer ${ }^{(\mathbf{1})}$. Cancer associated pain commonly occurs in malignancies involving the chest. It has been noted that about $5 \%$ of patients of pain clinics are of thoracic pain sufferers ${ }^{(2)}$. Thoracic pain may arise from a variety of structures such as the thoracic spine, referred from chest or upper abdomen, thoracic pain syndromes, or iatrogenic chronic chest pain following thoracic surgical procedures ${ }^{(3)}$. Chest wall pain is a severe and disabling symptom; over half of lung cancer patients are suffering from chest pain at diagnosis ${ }^{(4)}$. Chest pain in cancer patients can be multifactorial, making it complex; visceral, nociceptive, neuropathic or somatic. Thoracic pain of chronic nature may be controlled by pharmacotherapy, palliative radiotherapy, physiotherapy, occupational therapy or interventional therapy ${ }^{(5)}$.Untreated cancer pain is associated with both physical and psychological problems which cause suffering. Patients with uncontrolled pain have physical symptoms such as: anorexia, insomnia, prolonged fatigue, reduced cognition and an overall reduction in their vital capacity. Cancer patients with unrelieved pain tend to withdraw themselves from both social and family interactions, which lead to isolation and psychological distress ${ }^{\left({ }^{(6}\right.}$.Recent therapeutic advances allowed an increase in the survival rate of cancer patients; therefore making lung cancer a chronic condition ${ }^{(7)}$. With the increase in cancer prevalence, plus the increase in number of cancer patients with refractory chest pain and also prolonged life expectancy there is a demand for interventional procedures to control their pain ${ }^{(5)}$.

Interventional pain procedures are indicated for refractory pain when analgesic drugs become ineffective or are associated with intolerable sideeffects. These interventions vary from simple intercostal nerve blockade up to percutanous cervical cordotomy (PCC) and rhizotomy ${ }^{(5)}$. Radiofrequency ablation is of use due to its efficacy, safety and ease of use. It also requires only minimal hospital stay or can be even done as an outpatient procedure ${ }^{\left({ }^{(8)}\right.}$.

Aim of the Study: 
This study was designed to test both the efficacy and safety of thermo-coagulative ablation of the thoracic dorsal root ganglia for pain control in cancer patients that have refractory chest pain.

Patients and Methods:

\section{Design of the study}

This prospective randomized study was conducted in the National Cancer Institute, Cairo University and Aswan University after board approval from October 2016 to March 2018. Sixtyfive patients with Refractory Chronic Chest Cancer Pain were selected randomly and prospectively from the pain clinic of both the National Cancer Institute of Cairo University and Aswan University, after taken an informed written consent from the patient. These patients were selected according to the following criteria:

\section{Inclusion criteria:}

1. Patient Age $>18$ years with refractory chronic chest pain

2. VAS (Visual Analogue Score) $>$ or 5

3. Distribution of pain between dermatomes T2 - T8

4. Refractory chronic pain in the thoracic region > or of 3 months, and not responding to analgesics and adjuvants.

Pain is defined as refractory, regardless of etiology (9). Multiple evidence-based biomedical therapies used in a clinically appropriate and acceptable fashion have failed to reach treatment goals that may include adequate pain reduction and/or improvement in daily functioning or have resulted in intolerable adverse effects

\section{Exclusion criteria:}

1. Refusal of the patient

2. Uncooperative patient or patient unable to lie prone

3. Psycho-mental disorders

4. Pregnancy

5. Allergy to medication (local anesthetic, contrast material, glucocorticoids)

6. Intraspinal -intramedullary tumor (especially in mesothelioma after excision of intramedullary extension by MRI or $\mathrm{Ct}$ contrast)

7. Evidence of neurological deficit

8. Severe cardio-respiratory compromise

9. Local or systemic infection

10. Coagulopathy (uncorrectable)

\section{TECHNIQUE:}

The procedure was done in the intervention theatre, which was equipped with all necessary resuscitation equipment, after obtaining a written informed consent.

- POSITION: patient was laid in prone position on a radio-lucent table and with a small pillow under the chest to relax the back muscles.
- After sterile preparations and draping - the selected dermatome(s) (T2:T8) was checked by the history taken, clinical examination and local rib tenderness under the fluoroscopy.

- The technique was performed by using a dorsal approach as described by Waldman ${ }^{(\mathbf{1 0})}$.

\section{- Counting levels:}

Patient was placed on a true postero-anterior view of the $\mathrm{C}$-arm and then the ribs were counted either from cranial to caudal or from caudal to cranial direction.

- ALIGNMENT of LOWER END PLATE: - after determining the desired level and in true posteroanterior view, then by moving the $\mathrm{C}$-arm slightly cephalic the lower end plate of the targeted of the targeted level(s) was aligned as one line or for there to be no more double contour.

- OBLIQUE VIEW: the C-arm was tuned obliquely from 5 to $15^{\circ}$ (Fig. 1) towards the ipsilateral side to expose the intervertebral foramen (sub-pedicular foramen or safe triangle).

- ENTRY POINT: within the safe triangle, and after infiltrating the skin, subcutaneous tissues and musculature with $1 \%$ lidocaine we introduced the needle under articular pillar at the lower $1 / 3$ of the lateral vertebral margin, so that the entry point was located just below the halo of the transverse process and medial to the $4 \mathrm{~cm}$ rule of the thoracic procedures; this is to avoid injury of the parietal pleura (Fig. 1).

- Radiofrequency needles were then introduced on the targeted dorsal root ganglion (DRG) by using the tunnel vision technique (Trajectory Tunnel Technique) (Fig. 2). It was localized to the dorsocranial quadrant of the intervertebral formina.

- The needles final positions were confirmed after injection of 0.2 to $0.4 \mathrm{ml}$ of the non-ionic contrast dye (Omniopaque).

- DEAD LATERAL VIEW: the dead lateral view of the C-arm was taken to check needle depth. Then the needle was carefully advanced into the intervertebral formen. Ideally to be in the upper or mid dorsal zone up to the centre of the foramen to avoid injury of the segmental artery (Figs. 4 \& 5).

- A-P VIEW again: the A-P view was then checked again to assure the medial direction of the needles and to confirm that there was no angulations of needles (Fig.3).

- INJECTION of the DYE: after negative aspiration of blood, air or CSF, 0.2 to $0.4 \mathrm{ml}$ of the non-ionized contrast dye (omnipaque TM) was injected to delineate the dorsal selected nerve root, intercostals nerve path and the epidural spread. This is confirmed at A-P and lateral views (Fig. 6). 


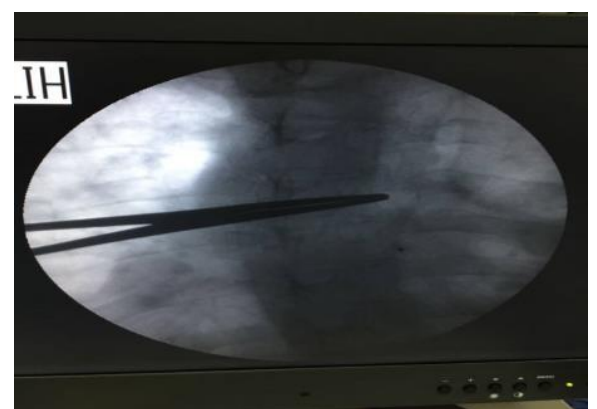

Fig. 1: oblique view $\left(15^{0}\right)$ site of needle entry at the

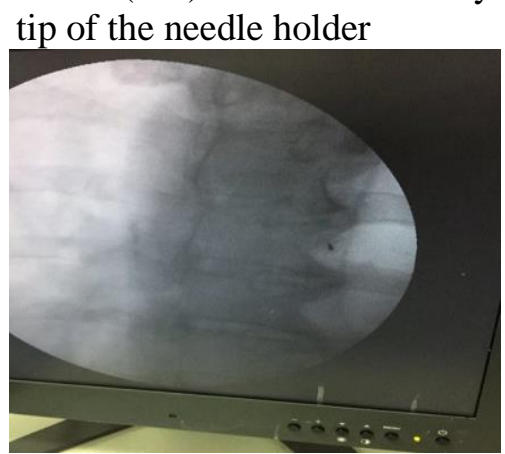

Fig. 2: oblique view $\left(15^{0}\right)$ introducing RF needle (end-on) under the articular pillar

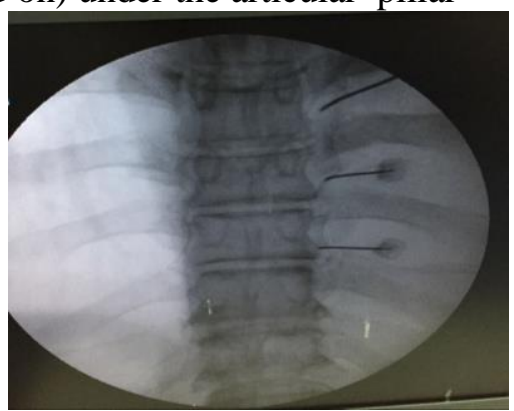

Fig. 3: a P view confirming the needle position (the tip of the needle is directed medially)

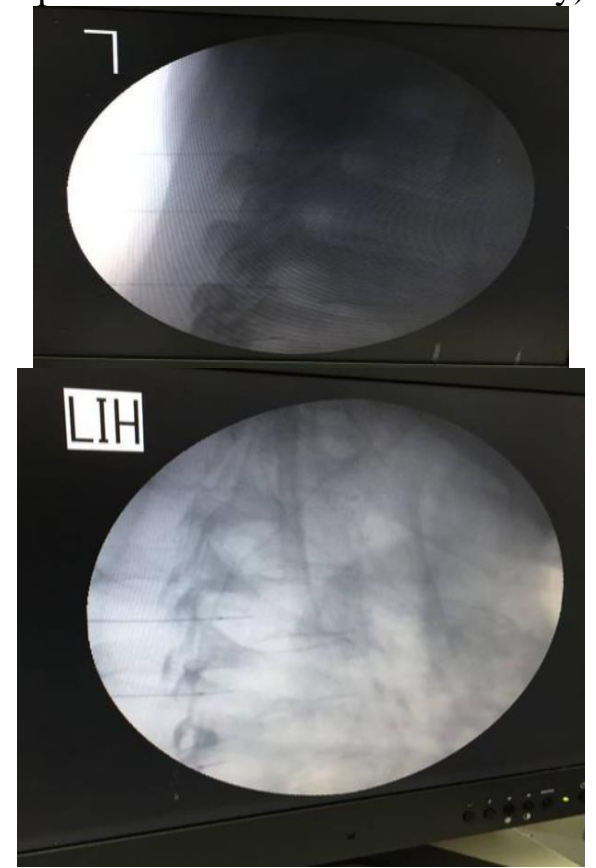

Figs. 4, 5: RF needles in the intervertebral foramina (Lateral view)
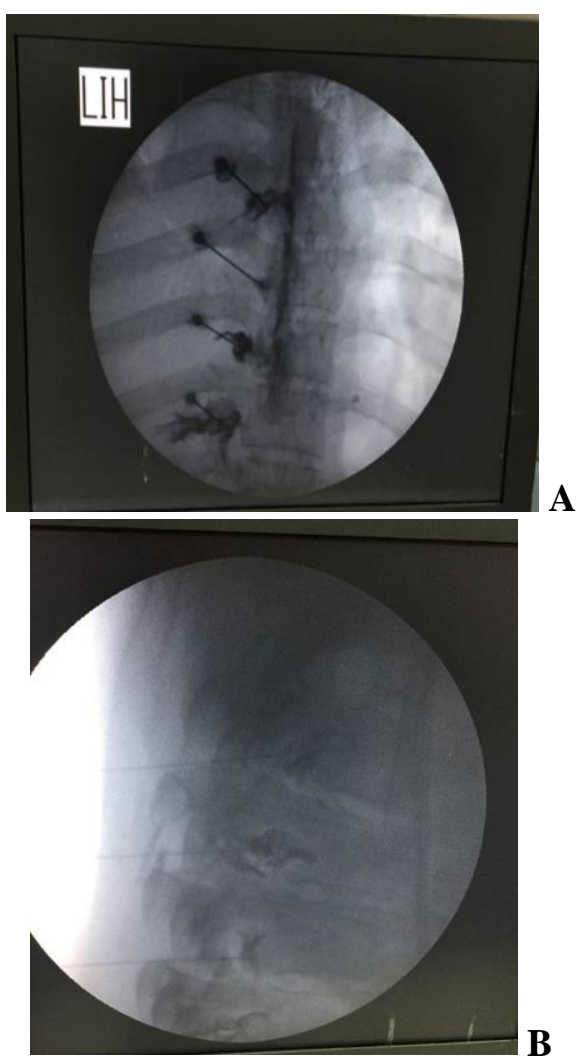

Fig. 6 : A- Antero-posterior view and B- Lateral view of the final position of the RF needles after injection of non-ionic contrast dye.

\section{RADIOFREQUENCY STIMULATION:}

\section{A. Sensory Stimulation:}

- After replacing the RF needle trocar with the thermocouple electrode, sensory stimulation was done at $50 \mathrm{~Hz}$, if tingling and parathesia sensation was reported at the targeted dermatome(s) at 0.4 to 0.6 volts, this means that the needles were at the physiological correct positions; i.e. adjacent to DRG. But if stimulation and tingling was reported to be less than 0.4 volts, this means intraganglionic position of the needles.

\section{B. Motor Stimulation:}

- Motor stimulation at $2 \mathrm{~Hz}$, if the intercostals muscle contraction or fasciculators (ideally medial to the needles) was reported this means that the needles were at the physiological correct position i.e. so close to the DRG.

- Also impedance was observed; usual range from 200:300 Ohm near DRG.

\section{BEFORE THERMAL RADIO-} FREQUENCY (TRF)LESIONING: at each level $2 \mathrm{ml}$ of lidocane $2 \%$ together with $2 \mathrm{mg}$ of betamethasone sodium phosphate and $5 \mathrm{mg}$ of betamethasone dipropionate were injected and after 3 minutes TRF lesioning was done. Propofol shots were given during TRF application. 


\section{RADIOFREQUENCY LESIONING:}

after confirming the needles positions, two lesions were done each at $80^{\circ}$ for 90 seconds, both superomedial and infero-medial directions to ensure thermal destruction of the DRG.

AFTER the PROCEDURE: all patients were transferred to the recovery room to ensure hemodynamic stability and to exclude potential complications e.g. neurological, pneumothorax, hematoma....etc. Then patients were advised to continue their pharmacological pain therapy.

\section{Evaluation parameters}

Each patient's pain was evaluated by the following assessments:

\section{Visual Analogue Scale:}

Patients were asked to choose a number that relates to their pain intensity: 0 at the left $=$ no pain and 10 at the right end $=$ the worst possible pain,(1$3)=$ mild,$(4-7)=$ moderate,$(8-10)=$ severe. Patients point the number on the scale which represents their pain level.

\section{Visual Analogue Scale (VAS) Reduction}

VAS reduction, measures functional improvement were:

1. VAS score improvement $>75 \%$ was considered a successful block with excellent response.

2. VAS score improvement $50-75 \%$ was considered a successful block with good response.

3. VAS score improvement $25-50 \%$ was considered an unsuccessful block with fair response.

4. VAS score improvement $<25 \%$ was considered an unsuccessful block with poor response.

\section{Duration of Treatment and Follow Up:}

Each patient was assessed pre-interventional and post-interventional; after 1 week, 1 month and after 3 months for comparison (Pre-interventional state versus Post-interventional state) based on the following:

\section{Data Collection and Interpretation:}

1. Demographic Data (Pre-Interventional data):
a. Age
b. Gender
c. Basic character of pain:
i. Type of pain:
- Neuropathic burning
- Neuropathic lancinating, tingling

- Neuropathic tingling

- Neuropathic tingling, electric

- Neuropathic tingling, numbness

- Nociceptive dull ache

ii. Side of pain:

- Left

- Right

iii. Cause of pain:

- Adenocarcinoma

- Bronchogenic

- Methoselioma

- Non-small cell carcinoma

- Post Thoracotomy

Adenocarcinoma

- Post Thoracotomy

Mesotheloma

- Small cell carcinoma

iv. Number of affected dermatomes

d. Basic drug consumption:

i. Oxycodone

ii. Pregabalin

e. VAS

iii. Amitriptyline

f. ECOG Performance Scale

2. Evaluation Data:

The following data was collected, by a junior pain resident who was blinded to the study.

\section{A. Primary Outcome}

a. Pain assessment using VAS (Visual Analogue Scale)

b. VAS Reduction (Functional ImprovementPost-interventional)

c. Dose of opioids and adjuvant medications consumption:

$$
\begin{aligned}
& \text { i. Oxycodone } \\
& \text { ii. Pregabalin } \\
& \text { iii. Amitriptyline }
\end{aligned}
$$

\section{B. Secondary Outcome}
a. Patient Satisfaction
b. ECOG Performance Status (Functional Activity)

\section{Side effects and Complications (Post- Interventional data):}
a. Numbness
b. Dorsal back pain
c. Neuritis
d. Infection
e. Pneumothorax
f. Motor affection
g. Differentiation pain 


\section{RESULTS}

In this study sixty-five patients were selected from the pain clinics of the National Cancer Institute, Cairo University and Aswan University. But, only sixty-two patients completed the follow-up system until the end which was 3 months post-interventional. Based on the data collected the following results were obtained.

Table 1- Patient Demographic Characteristics

\begin{tabular}{|c|c|c|c|c|c|}
\hline & Mean & $\begin{array}{c}\text { Standard } \\
\text { Deviation }\end{array}$ & Median & Minimum & Maximum \\
\hline Age & 54.16 & 7.45 & 56.00 & 40.00 & 64.00 \\
\hline
\end{tabular}

\begin{tabular}{|c|c|c|c|}
\hline & & Count & $\%$ \\
\hline \multirow[t]{2}{*}{ age groups } & $>50$ years & 39 & $62.9 \%$ \\
\hline & $<50$ years & 23 & $37.1 \%$ \\
\hline \multirow{2}{*}{ Sex } & Male & 36 & $58.1 \%$ \\
\hline & Female & 26 & $41.9 \%$ \\
\hline \multirow{6}{*}{ Type of pain } & Neuropathic burning & 6 & $9.7 \%$ \\
\hline & Neuropathic lancinating, tingling & 4 & $6.5 \%$ \\
\hline & Neuropathic tingling & 4 & $6.5 \%$ \\
\hline & Neuropathic tingling, electric & 8 & $12.9 \%$ \\
\hline & Neuropathic tingling, numbness & 4 & $6.5 \%$ \\
\hline & Nociceptive dull aching & 36 & $58.1 \%$ \\
\hline \multirow{8}{*}{ Cause of pain } & Adenocarcinoma & 9 & $14.5 \%$ \\
\hline & Bronchogenic & 4 & $6.5 \%$ \\
\hline & Mesotheloma & 35 & $56.5 \%$ \\
\hline & Non-small cell carcinoma & 1 & $1.6 \%$ \\
\hline & Post-Thoracotomy Mesotheloma & 1 & $1.6 \%$ \\
\hline & Post-Thoracotomy Adenocarcinoma & 4 & $6.5 \%$ \\
\hline & Small cell Carcinoma & 6 & $9.7 \%$ \\
\hline & Breast Cancer & 2 & $3.2 \%$ \\
\hline \multirow{4}{*}{$\begin{array}{l}\text { Number of affected } \\
\text { dermatomes }\end{array}$} & 1 dermatome & 4 & $6.5 \%$ \\
\hline & 2 dermatomes & 16 & $25.8 \%$ \\
\hline & 3 dermatomes & 24 & $38.7 \%$ \\
\hline & 4 dermatomes & 18 & $29.0 \%$ \\
\hline
\end{tabular}

Based on the data above the greater part of our patients were in the age group above 50 years old, males with 3 or 4 dermatomes affected. 
Table 2- Pre-Interventional Assessment

\begin{tabular}{|l|c|c|c|c|c|}
\hline & Mean & $\begin{array}{c}\text { Standard } \\
\text { Deviation }\end{array}$ & Median & Minimum & Maximum \\
\hline VAS before & 7.94 & .85 & 8.00 & 6.00 & 9.00 \\
\hline QOLS before & 1.32 & 1.11 & 1.00 & .00 & 3.00 \\
\hline ECOG scale before & 3.58 & .50 & 4.00 & 3.00 & 4.00 \\
\hline Pregabalin mg before & 234.68 & 88.52 & 250.00 & 100.00 & 450.00 \\
\hline oxycodone mg before & 71.61 & 41.06 & 60.00 & 40.00 & 160.00 \\
\hline amitriptylinemg before & 23.79 & 4.12 & 25.00 & 10.00 & 25.00 \\
\hline
\end{tabular}

Table 3- Visual Analogue Scale

\begin{tabular}{|l|c|c|c|c|c|c|}
\hline & Mean & $\begin{array}{c}\text { Standard } \\
\text { Deviation }\end{array}$ & Median & Minimum & Maximum & $\begin{array}{c}\text { P value } \\
\text { compared } \\
\text { to before }\end{array}$ \\
\hline VAS before & 7.94 & .85 & 8.00 & 6.00 & 9.00 & -- \\
\hline VAS after 1 week & 2.32 & 1.17 & 2.00 & 1.00 & 4.00 & $<0.001$ \\
\hline VAS after 1 month & 1.95 & 1.05 & 2.00 & 1.00 & 4.00 & $<0.001$ \\
\hline VAS after 3 months & 2.53 & 1.13 & 3.00 & 1.00 & 4.00 & $<0.001$ \\
\hline
\end{tabular}

Table 4- VAS Reduction (Functional improvement)

\begin{tabular}{|l|c|c|c|c|c|}
\hline & Mean & $\begin{array}{c}\text { Standard } \\
\text { Deviation }\end{array}$ & Median & Minimum & Maximum \\
\hline VAS Reductionafter 1 week & 70.55 & 15.36 & 75.00 & 42.86 & 88.89 \\
\hline VAS Reduction after 1 month & 75.44 & 13.30 & 77.78 & 42.86 & 88.89 \\
\hline $\begin{array}{l}\text { VAS Reductionafter 3 } \\
\text { months }\end{array}$ & 67.75 & 15.22 & 66.67 & 42.86 & 88.89 \\
\hline
\end{tabular}

\begin{tabular}{|l|c|c|c|c|c|c|}
\hline & \multicolumn{2}{|c|}{$\begin{array}{c}\text { VAS Reductionafter 1 } \\
\text { week }\end{array}$} & \multicolumn{2}{c|}{$\begin{array}{c}\text { VAS Reduction after 1 } \\
\text { month }\end{array}$} & \multicolumn{2}{c|}{$\begin{array}{c}\text { VAS Reductionafter 3 } \\
\text { months }\end{array}$} \\
\hline & Count & $\%$ & Count & $\%$ & Count & $\%$ \\
\hline excellent & 25 & $40.3 \%$ & 36 & $58.1 \%$ & 19 & $30.6 \%$ \\
\hline Good & 31 & $50.0 \%$ & 24 & $38.7 \%$ & 35 & $56.5 \%$ \\
\hline fair & 6 & $9.7 \%$ & 2 & $3.2 \%$ & 8 & $12.9 \%$ \\
\hline poor & 0 & $.0 \%$ & 0 & $.0 \%$ & 0 & $.0 \%$ \\
\hline
\end{tabular}

Based on the above data, there was a significantly noticeable reduction in pain severity regarding VAS after 1 week, with maximum reduction after 1 month. 
Table 5- Drug Consumption:

Table 5a- Pregabalin:

\begin{tabular}{|l|c|c|c|c|c|c|}
\hline & Mean & $\begin{array}{c}\text { Standard } \\
\text { Deviation }\end{array}$ & Median & Minimum & Maximum & $\begin{array}{c}\text { P value } \\
\text { compared } \\
\text { to before }\end{array}$ \\
\hline $\begin{array}{l}\text { Pregabalin mg } \\
\text { before }\end{array}$ & 234.68 & 88.52 & 250.00 & 100.00 & 450.00 & --- \\
\hline $\begin{array}{l}\text { Pregabalin mg } \\
\text { after 1 week }\end{array}$ & 232.26 & 87.82 & 200.00 & 100.00 & 450.00 & 0.781 \\
\hline $\begin{array}{l}\text { Pregabalin mg } \\
\text { after 1 month }\end{array}$ & 217.74 & 75.80 & 200.00 & 100.00 & 450.00 & 0.164 \\
\hline $\begin{array}{l}\text { Pregabalin mg } \\
\text { after 3 months }\end{array}$ & 224.19 & 77.75 & 200.00 & 100.00 & 450.00 & 0.487 \\
\hline
\end{tabular}

Based on the above results on Pregabalin, the maximum reduction in dose was noticed after 1 month with a slight increase in dose after 3 months post-interventional. But considered to be insignificant p value $>0.05$.

Table 5b- Oxycodone

\begin{tabular}{|l|c|c|c|c|c|c|}
\hline & Mean & $\begin{array}{c}\text { Standard } \\
\text { Deviation }\end{array}$ & Median & Minimum & Maximum & $\begin{array}{c}\text { P value } \\
\text { compared } \\
\text { to before }\end{array}$ \\
\hline $\begin{array}{l}\text { oxycodone mg } \\
\text { before }\end{array}$ & 71.61 & 41.06 & 60.00 & 40.00 & 160.00 & --- \\
\hline $\begin{array}{l}\text { oxycodone mg } \\
\text { after 1 week }\end{array}$ & 70.32 & 39.46 & 60.00 & 40.00 & 160.00 & 0.139 \\
\hline $\begin{array}{l}\text { oxycodone mg } \\
\text { after 1 month }\end{array}$ & 59.35 & 23.74 & 40.00 & 40.00 & 160.00 & 0.126 \\
\hline $\begin{array}{l}\text { oxycodone mg } \\
\text { after 3 months }\end{array}$ & 69.03 & 37.75 & 60.00 & 40.00 & 160.00 & 0.781 \\
\hline
\end{tabular}

According to the results on Oxycodone drug consumption, maximum dose reduction was after 1 month while at 3 months there was an increase in dose. Results are insignificant because $\mathrm{P}$ value $>0.05$.

Table 5c- Amitriptyline

\begin{tabular}{|l|c|c|c|c|c|c|}
\hline & Mean & $\begin{array}{c}\text { Standard } \\
\text { Deviatio } \\
\mathbf{n}\end{array}$ & Median & $\begin{array}{c}\text { Minimu } \\
\mathbf{m}\end{array}$ & $\begin{array}{c}\text { Maximu } \\
\mathbf{m}\end{array}$ & $\begin{array}{c}\text { P value } \\
\text { compare } \\
\mathbf{d} \text { to } \\
\text { before }\end{array}$ \\
\hline $\begin{array}{l}\text { amitriptylinemg } \\
\text { before }\end{array}$ & 23.79 & 4.12 & 25.00 & 10.00 & 25.00 & --- \\
\hline $\begin{array}{l}\text { amitriptylinemg } \\
\text { after 1 month }\end{array}$ & 23.06 & 5.07 & 25.00 & 10.00 & 25.00 & 0.083 \\
\hline $\begin{array}{l}\text { amitriptylinemg } \\
\text { after 3 months }\end{array}$ & 21.85 & 6.16 & 25.00 & 10.00 & 25.00 & 0.065 \\
\hline $\begin{array}{l}\text { amitriptylinemg } \\
\text { before }\end{array}$ & 23.31 & 4.79 & 25.00 & 10.00 & 25.00 & 0.157 \\
\hline
\end{tabular}


With Amitriptyline drug consumption, the dose was maximally reduced after 1 month, with an increase in the dose after 3 months post-interventional.However, the results are insignificant since the $\mathrm{P}$ value $>0.05$.

Table 6- Complications

\begin{tabular}{|l|c|c|c|}
\hline \multirow{3}{*}{ Numbness } & & Count & $\%$ \\
\hline \multirow{3}{*}{ Dorsal back pain } & yes & 7 & $11.3 \%$ \\
\cline { 2 - 4 } & no & 55 & $88.7 \%$ \\
\hline \multirow{3}{*}{ Neuritis } & yes & 0 & $.0 \%$ \\
\cline { 2 - 4 } & no & 62 & $100.0 \%$ \\
\hline \multirow{3}{*}{ Infection } & yes & 7 & $11.3 \%$ \\
\cline { 2 - 4 } & no & 55 & $88.7 \%$ \\
\hline \multirow{2}{*}{ Pneumothorax } & yes & 0 & $.0 \%$ \\
\cline { 2 - 4 } & no & 62 & $100.0 \%$ \\
\hline \multirow{2}{*}{ Motor affection } & yes & 0 & $.0 \%$ \\
\cline { 2 - 4 } & no & 62 & $100.0 \%$ \\
\hline \multirow{2}{*}{ Differentiation pain } & yes & 0 & $.0 \%$ \\
\cline { 2 - 4 } & no & 62 & $100.0 \%$ \\
\hline
\end{tabular}

Based on the results, the only significant complications reported were numbness and neuritis.

\section{DISCUSSION}

Cancer and pain are clinical entities closely associated. Recent reviews suggest there to be a prevalence of pain in about $51 \%$ of cancer patients regardless of type and stage. This prevalence increases with the type of tumor; head and neck, lung, breast cancers are the ones with higher prevalence, and with the staging; advanced, metastatic or terminal reaching a $66 \%$ of cases ${ }^{(1)}$.

With recent therapeutic advances, it has allowed an increase in the survival rates potentially turning lung cancer into a chronic condition ${ }^{(2)}$. Since pain is also present in up to $39 \%$ of cases after curative intent, an increased survival could impact this number of patients left with persistent symptoms despite being successfully treated. As the number of cancer patients with refractory chest pain is increasing with more cancer prevalence, therapy advances and prolonged life expectancy, the becomes a demand for interventional procedures to help control, these cases were also increased ${ }^{(2)}$.

An interventional pain procedure is usually indicated when (1) the patient has not reached satisfactory analgesic control despite optimal conventional medical management as suggested by the WHO guidelines or (2) When adequate pain control is associated with intolerable side-effects ${ }^{\mathbf{( 1 1})}$. Other indications include (3) favoring analgesic control with opioid sparing techniques or (4) analgesia in patients that are poor candidates to opioid analgesia. Interventional pain procedures should be offered to patients before they are too fragile to undergo the procedure, thus they should not be considered an option but rather as part of an analgesic strategy ${ }^{(\mathbf{1 2})}$. There are 2 modalities of intraspinal procedures that are available to manage drug resistant pain $2^{\text {ry }}$ to cancer, either continuous spinal drug delivery or spinal neurolytic procedures. Drugs are injected directly into the spinal canal thus achieving more potent analgesic effects with minimal doses. Also, the effect may be restricted to few dermatomes, therefore sparing the possible sideeffects to a targeted anatomical area. However, it is associated with uncontrolled intra-spinal spread and high risk for neurological deficits which limit its clinical use ${ }^{\left({ }^{13)}\right.}$.Electrical neurostimulation use is of limitation due to its cost, the indication in cancer pain patients is usually restricted to those cases, when 
cancer has been successfully cured but patients are left with painful permanent consequences ${ }^{(14)}$. Even though in the past, neurosurgical destructive procedures for cancer pain were considered the main line of treatment therapy in the previous 2 centuries, now of limitation due to their extensive complications. Neurosurgical procedures such as percutaneous cervical cordotomy have been replaced with the availability of opioids, coadjuvants and newer anesthetic techniques due to technique difficulty, and complications which are significant; such as $3 \%$ mortality, $11 \%$ motor weakness and other complications which include: respiratory, bladder dysfunction, postcordotomy hypotension, sexual dysfunction, sensory changes and dysethesia ${ }^{(\mathbf{1 5})}$.

In our study we decided to test both the efficacy and safety of thermocoagulative ablation of thoracic dorsal root ganglia for pain control in this category of patients. Chest pain in cancer patients can be multifactorial, visceral, nociceptive, or neuropathic. Our study has shown that thermal radiofrequency lesioning of thoracic dorsal root ganglia was effective in relief of pain since there was a significant reduction of mean VAS values after the procedure in all the follow up measurements. Thermal radiofrequency ablation of the dorsal root ganglia (TRF-DRG) causes thermocoagulative necrosis of the nerve fibers that denaturate the nerves to interrupt noxious input. It was suggested that even long term central sensitization can be reversed quickly The use of TRF for managing nonmalignant pain is becoming of controversy due to its potential hazards such as neuritis, deafferentation pain and motor deficits but it has been postulated that TRF therapeutic effect was attained through partial nerve lesion ${ }^{(16)}$.Therefore, the significant thermal lesioning of the thoracic DRG which was done, together with the sensory overlap phenomenon of the thoracic dermatomes, all explain the absence of deafferantation pain following TRF-DRG in our study. As for the motor deficits, TRF-DRG apart from $\mathrm{T} 1$ is not risky for motor power of the limbs in contrast to cervical and lumber DRGs. The selected dermatomes in our study were T2-T8 thoracic segments DRG. T1 was not involved due to the fear of motor deficits (being involved in the brachial plexus formation). The thoracic dermatomes T9-T12 were excluded from our study to avoid major complications associated with lower thoracic transformainal approach. In the thoracic portion, the intercostal arteries (from the posterior aorta) feed the radicular arteries which represent a major supply of the spinal cord blood flow. The upper thoracic cord is supplied by a small radiculomedullary artery and is a watershed area. While, the lower thoracic cord is supplied almost entirely by the large unpaired artery of Adam Kiewicz, making this region vulnerable to ischemic injury. This artery arises between T9-T12 in $85 \%$ of people usually on the left side ${ }^{(17)}$. In a study decided to select thermal and not pulsed radiofrequency (PRF), firstly, as the onset of beneficial effect is delayed in PRF for 3 to 4 weeks ${ }^{(18)}$ which could not be waited for in cancer patients with unbearable pain. Second, PRF has been associated with only short term pain relief ${ }^{(\mathbf{1 9})}$. In the study, we used betamethasone as an adjuvant to TRF for its beneficial effects in neuropathic pain and also to reduce the incidence of post procedure neuritis and differentiation pain. Betamethasone as a nonparticulate preparation was chosen to reduce the vascular, thromboembolic hazards associated with the use of particulate steroids ${ }^{(20)}$. Our technique of transforminal needling of the thoracic DRG has many benefits in comparison to the classic approach (21) 1- less patient discomfort as little bone contact and less periosteal irritation, 2- more medial approach with less risk of pneumothorax, 3- more medial path of needle entry so the intervertebral foramen is directly assessed. The radiofrequency needle selected with a number of parameters, $100 \mathrm{~mm}$ length to suit obese patients and those with thick back musculature, $10 \mathrm{~mm}$ active tip augment the lesion size, sharp to facilitate skin puncture and to reduce vascular and neuronal damage ${ }^{(22)}$, with curved tip to facilitate delicate and discrete changes of direction and rotation during insertion and finally with radio-opaque knob to delineate the proximal end of the active tip, so there is better control of the location and size of the lesion to ensure safety and minimize collateral damage to TRF energy ${ }^{(23)}$. No prognostic intercotsal block with local anesthetic was given intentionally prior to TRF-DRG as clinical role of diagnostic block is questionable and not warranted in patients with terminal malignancy ${ }^{(24)}$.

The "Kambin's triangle" is an alternative to the subpedicular "safe triangle" approach, especially when placement of the needle is difficult by the subpedicular technique. Kambin's triangle is the superior endplate of the inferior vertebral body (base of the triangle), the superior articulating facet (height of the triangle) and the superior nerve root (the hypotenous of the triangle $)^{(26)}$. Our results are similar to other studies done by Stolker et al. ${ }^{(26)}$ and Van Kleef $\boldsymbol{e t} \boldsymbol{a l}{ }^{(27)}$ Stolker $\boldsymbol{e t} \boldsymbol{a l} .{ }^{(26)}$ evaluated RF in 45 patients with chronic thoracic segmental pain nonresponsive to standard treatment and concluded that this procedure may prove as an effective and safe therapy for this situation ${ }^{(26)}$. While, Van Kleef $\boldsymbol{e t} \boldsymbol{a l}$. (27) evaluated 43 patients with unilateral segmental chronic chest pain undergoing TRF-DRG and concluded that a significant both short and long term pain relief were attained which was better for localized pain (to 1 or 2 segments) than nonlocalized pain. Van Kleef's opinion was that RF- 
DRG should be restricted to nociceptive pain syndromes and little efficacy in neuropathic syndromes with sensory loss due to neuronal damage such as post-thoracotomy, post-mastectomy, and post-herpetic pain syndromes ${ }^{(27)}$. With regards to our study, we found that with effective pain relief there was a significant reduction of mean VAS values; which means that there was functional improvement, in all the post-interventional follow up. Also O'Connor ${ }^{(28)}$ documented in his study that with significant pain reduction it provides indirectly the patient with a new life. Pharmacological control of neuropathic pain is not an easy process even if a mix of pain killers, opioids and adjuvant drugs are used .This forces many pain organizations and institutes to develop a protocol for neuropathic pain NP management. So the Neuropathic Pain Special Interest Group of the International Association for the study of pain recently sponsored the development of evidence based guidelines for pharmacological treatment of neuropathic pain with reasonable side effects ${ }^{(29)}$.

The difficulty in controlling neuropathic pain with medical treatment even when following the protocol recommendations was a common problem. Therefore the development of other protocols for the use of minimally invasive pain relief interventions becomes a must. These interventions can be considered invasive procedures involving the delivery of drugs into the targeted areas, or ablation of targeted nerves for the control of pain ${ }^{(29)}$.

Interventional management of cancer pain does not replace other modalities but can be an alternative to improve pain control and allow for reduction in the number of systemic medication or dose consumption and their side-effects. There were unfavorable side-effects from the use of oral or parenteral opioids ${ }^{(30)}$.

Based on our study, drug consumption doses of pregabalin, oxycodone and amitriptyline showed a maximum reduction after 1 month with a slight increase in the following follow up which was 3 months post-interventional. However, this slight increase in dose still remained overall lower than pre-interventional doses. But it is important to note that, regarding the reduction, our results prove that the reduction is considered insignificant since our $P$ values turned out to be $>0.05$, therefore insignificant.

With regards to our study, patient satisfaction was found to be, with the first question "If you could go back in time, would you like to repeat the procedure?"30.6\% certainly would repeat it, $54.8 \%$ probably would, and $12.9 \%$ probably would not while only $1.6 \%$ certainly would not repeat this procedure.
While, with the second question "would you recommend the same procedure to a family member or friend?"25.8\% certainly would recommend it, $56.5 \%$ probably would, $14.5 \%$ probably would not and only $3.2 \%$ certainly would not recommend it. Therefore Thermal Radiofrequency ablation is considered an alternative to control cancer pain because of its efficacy, safety and ease of use. It also requires a minimal hospital stay or can even be performed on an outpatient basis ${ }^{(31)}$.

Conclusion:

We concluded that thermal radiofrequency ablation is considered an alternative for treating Refractory Chronic Chest Cancer pain of several types and causes. This is because of its efficacy, safety and ease of use. It also requires a minimal hospital stay or can even be performed on an outpatient basis.

\section{REFERENCES}

1. Van den Beuken-van Everdingen $M H$, Hochstenbach LM, Joosten EA et al. (2016): Update on prevalence of pain in patients with cancer: systematic review and metaanalysis. J. Pain. Symptom. Manage., 51(6):1070-1090.

2. Kleef V, Zundert V, Eder $M$ et al. (2014): Radiofrequency treatment. Practical Management of Pain, 62: 846-866.

3. Bonica JJ and Sola AE (1990): Chest pain caused by other disorders. In: The management of pain. Bonica JJ, Loeser Jd, Chapman CR, Fordyce WE, eds. $2^{\text {nd }}$ ed. Philadelphia.pp:1114-1145.

4. Chute CG, Greenberg ER, Baron J et al. (1985): Presenting conditions of 1539 population- based lung cancer patients by cell type and stage in New Hampshire and Vermont. Cancer, 56:2107-2111.

5. Wouter WA, Zuurmond RS, Stephen AL et al. (2010): Role of cervical cordotomy and other neurolytic procedures in thoracic cancer pain. Curr. Opin. Support. Palliat. Care, 4: 6-10.

6. Pergolizzi JV, Gharibo C and Ho KY (2015): Treatment considerations for cancer pain: a global perspective. Pain Pract., 15:778-7792.

7. Aldarouish M and Wang C (2016): Trends and advances in tumor immunology and lung cancer immunotherapy. J. Exp. Clin. Cancer Res., 35:157-162.

8. Malik VS, Pan A, Willett WC et al. (2013): Sugarsweetened beverages and weight gain in children and adults: a systematic review and meta-analysis. The American Journal of Clinical Nutrition, 98(4):1084-1092.

9. Timothy RD, David LC and Mark SW (2014): A Definition of Refractory Pain to Help Determine Suitability for Device Implantation. Neuromodulation, 17(8): 711-715.

10. Waldman SD (2009): Atlas of Interventional Pain Management. Elsevier Health Sciences; Philidelphia: pp. 332.

11. Sindt JO, Camp PJ, Kantorovich SS et al. (2016): Influence of dipolar interactions on the magnetic susceptibility spectra of ferrofluids. Physical Review, 24 (6):63117-63120. 
12.Simpson KA (2011): Interventional techniques for pain management in palliative care. Medicine, 39:645-655.

13. Cohen SP, Sireci A, Wu CL et al. (2006): Pulsed radiofrequency of the dorsal root ganglia is superior to pharmacotherapy or pulsed radiofrequency of the intercostal nerves in the treatment of chronic postsurgical thoracic pain. Pain Physician, 9(3):227-230.

14.Peng L, Min S, Zejun Z et al. (2015): Spinal cord stimulation for cancer-related pain in adults. Cochrane Database of Systematic Reviews, 29: 6-12.

15. Raslan AM, Cetas JS, McCartney S et al. (2011): Destructive procedures for control of cancer pain: the case for cordotomy. J .Neurosurg., 114:155-70.

16. Racz $G$ and Ruiz-Lopez $R$ (2006): Radiofrequency procedures. Pain Pract., 6: 46-50.

17. White ML and El-Khour y GY (2002): Neurovascular injuries of spinal cord. Eur. J. Radiol., 42: 117-126.

18. Vanneste T, Van Lantschoot A, Van Boxem $K$ et al. (2017): Pulsed radiofrequency in chronic pain. Curr. Opin. Anaesthesiol., 30(5):577-582.

19. Ke M, Yinghui F, Yi J et al. (2013): Efficacy of pulsed radiofrequency in treatment of thoracic post-herpetic neuralgia from the angulus costa: A randomized double blinded controlled trial. Pain Physician, 16: 15-25.

20. Uchida KI (2009): Radiofrequency treatment of the thoracic para vertebral nerve combined with glucocorticoid for refractory neuropathic pain following breast cancer surgery. Pain Physician, 12: 277-283

21. Angthong $\mathrm{C}$, Chernchujit $\mathrm{B}$, Suntharapa $\mathrm{T}$ et al. (2011): Visual analogue scale foot and ankle: validity and reliability of Thai version of the new outcome score in subjective form. J. Med. Assoc. Thai., 94(8):952-959.

22. Bogduk N (2006): Sharp vs blunt needles. International spine interventional society white paper. Interventional Spine, 5: 7-13.
23.Joseph FJ (2008): Radiofrequency cannula with active tip radio-opaque marker; Image analysis for facet, gray ramus and dorsal root ganglion techniques. Pain Physician, 11: 863-875.

24. Yuen T S, Ng KF and Tsui SL (2002): Neurolytic celiac plexus block for visceral abdominal malignancy. Is prior diagnostic block warranted?. Anaesth. Intensive Care., 30: 442-448.

25.Park JW, Nam HS, Cho SK et al. (2011): Kambin's triangle approach of lumbar transforaminal epidural injection with spinal stenosis. Annals of Rehabilitation Medicine, 35(6):833-843.

26. Stolker RJ, Vervest AC and Groen GJ (1994): The treatment of chronic thoracic segmental pain by radiofrequency percutaneous partial rhizotomy. $\mathbf{J}$. Neurosurg., 80(6):986-992.

27. Van Kleef M, Barendse GA, Dingemans WA et al. (1995): Effects of producing a radiofrequency lesion adjacent to dorsal root ganglion in patients with thoracic segmental pain. Clin. J. Pain, 11(4): 325-332

28. O'Connor AB (2013): Neuropathic Pain. QOL impact, cost and cost effectiveness of therapy. Pharmaco Economics Journal, 27(2): 95-112.

29. Dworkin RH, O'Connor AB and Backonja M (2013): Pharmacologic management of neuropathic pain: evidence based recommendations. Pain, 132 (3): 237-251.

30. Claribel PL, MacLeod N and Barry JA (2012): Clinical Management of Pain in Advanced Lung Cancer. Clin. Med. Insights Oncol., 6:331-346

31. Tatli A and Özbilgin MF (2012): An emic approach to intersectional study of diversity at work. International Journal of Management Reviews, 14(2):180-200. 